\title{
Regulation of $S$-adenosylmethionine decarboxylase during the germination of sporangiospores of Mucor rouxii
}

\author{
Carlos Calvo-Mendez and Jose Ruiz-Herrera* \\ Departamento de Genética y Biología Molecular, Centro de Investigación y Estudios Avanzados, IPN, and Instituto de \\ Investigación en Biología Experimental, Universidad de Guanajuato, Apartado Postal 187, Guanajuato, Gto. 36000, \\ Mexico
}

(Received 2 August 1990; revised 9 October 1990; accepted 15 October 1990)

\begin{abstract}
General properties of $S$-adenosylmethionine decarboxylase (SAMDC) from Mucor rouxii were studied. Dormant spores of the fungus did not contain detectable levels of the enzyme, but it started to be synthesized at early stages of spore germination. Kinetics of synthesis changed before emergence of the germ tube, with a corresponding increase in a second SAMDC activity which, in contrast to the one originally synthesized, was not activated by putrescine. Development of the second enzyme activity required de novo protein synthesis. Neither enzymic activity was stimulated by $\mathrm{Mg}^{2+}$. Addition of the SAMDC inhibitor methylglyoxal bis-(guanylhydrazone) (MGBG) stopped fungal development in growth phase Ia: cells became spherical and showed ultrastructural alterations. Although MGBG inhibited polyamine formation, it barely inhibited protein and RNA biosynthesis during the first hour of incubation. However, at later periods, biosynthesis of both macromolecules was strongly decreased. When MGBG was added to growth media $3 \mathrm{~h}$ after inoculation of spores, it did not affect spore germination and outgrowth. A hypothesis for two different roles of spermidine and putrescine in spore germination is discussed.
\end{abstract}

\section{Introduction}

In previous communications we have reported that high levels of polyamines are required during the germination of sporangiospores of Mucor (Calvo-Mendez et al., 1987). In the presence of 1,4-diaminobutanone (DAB), an inhibitor of ornithine decarboxylase (ODC), spores are unable to proceed beyond phase Ib of spherical growth: they reach large diameters, and fail to produce germ tubes (Ruiz-Herrera \& Calvo-Mendez, 1987). For a description of growth phases during germination of Mucor sporangiospores see Bartnicki-Garcia \& Lippman (1977) and Cano \& Ruiz-Herrera (1988). We have presented evidence that the requirement for high polyamine concentrations during development of the fungus is related to DNA hypomethylation, a process occurring during DNA replication, and required for the differential expression of genes involved in polarized growth of the fungus (Cano et al., 1988).

In order to gain more information on the role of the different polyamines in Mucor development, we have investigated the regulation of $S$-adenosylmethionine

Abbreviations: SAM, $S$-adenosylmethionine; SAMDC, $S$-adenosyl methionine decarboxylase; ODC, ornithine decarboxylase; MGBG, methylglyoxal bis-(guanylhydrazone); DAB, 1,4-diamino-2-butanone. decarboxylase (SAMDC) during sporangiospore germination. SAMDC is responsible for the formation of decarboxylated $S$-adenosylmethionine, which serves as the aminopropyl donor to putrescine for the synthesis of spermidine (Mucor rouxii does not contain spermine: Nickerson et al., 1977; Ruiz-Herrera \& Calvo-Mendez, 1987). S-Adenosylmethionine decarboxylation constitutes one of the rate-limiting factors in spermidine formation, and is precisely regulated in several systems (Tabor \& Tabor, 1984; Pegg, 1986). Three different classes of SAMDC have been described with respect to activation of the enzyme by $\mathrm{Mg}^{2+}$ and putrescine. The enzyme from Escherichia coli and plants is activated by $\mathrm{Mg}^{2+}$ but not by putrescine. In contrast, the mammalian enzyme is activated by putrescine but does not require $\mathrm{Mg}^{2+}$, whereas slime mould and Tetrahymena pyriformis enzymes are activated by neither putrescine nor $\mathrm{Mg}^{2+}$ (Pegg, 1984). SAMDC from Saccharomyces and mycelial fungi behaves like the mammalian enzyme: it is activated by putrescine, but not by $\mathrm{Mg}^{2+}$ (Stevens $\&$ Winther, 1979).

In the present study we have investigated the general properties of SAMDC from Mucor rouxii, its regulation during the process of sporangiospore germination, and the effect of its in vivo inhibition on the development of the fungus. 


\section{Methods}

Strains, culture media and growth conditions. Mucor rouxii IM-80 (ATCC 24905) was maintained on slants of YPG medium, and propagated in liquid YPG medium or synthetic medium (BartnickiGarcia \& Nickerson, 1962), as described by Calvo-Mendez et al. (1987).

Preparation of cell-free extracts and toluene-permeabilized cells. These were prepared as described previously (Calvo-Mendez et al., 1987).

$S$-Adenosylmethionine decarboxylase (SAMDC) assays. Erlenmeyer flasks $(10 \mathrm{ml})$ containing a centre well were used for incubation. Enzyme preparations in phosphate buffer $\mathrm{pH} 7.5$ containing $0.1 \mathrm{~mm}-$ EDTA and $1 \mathrm{~mm}$-dithiothreitol (plus the additions indicated in each experiment) were dispensed into the outer chamber in a final volume of $395 \mu$ l. A piece of folded filter paper containing $35 \mu \mathrm{l} 5 \mathrm{M}-\mathrm{KOH}$ was placed in the centre well to trap the released $\mathrm{CO}_{2}$. The reaction was started by the addition of $0.2 \mathrm{~mm}(5 \mu \mathrm{l}) S$-adenosyl[ carboxyl $\left.{ }^{14} \mathrm{C}\right] \mathrm{meth}$ ionine (sp. act. $59 \cdot 5 \mathrm{Ci} \mathrm{mol}^{-1} ; 2 \cdot 2 \mathrm{TBq} \mathrm{mol}^{-1}$ ). The flasks were closed with rubber stoppers and incubated at $37^{\circ} \mathrm{C}$ for $60 \mathrm{~min}$. When anaerobic conditions were used, two needles were inserted through the stoppers and $\mathrm{N}_{2}$ was flushed through one of them for $5 \mathrm{~min}$; they were then simultaneously removed. Anaerobiosis was checked by incubation in parallel of a methyl viologen solution reduced with sodium dithionite. The reaction was stopped by injecting $100 \mu \mathrm{l}$ of $2 \mathrm{M}-\mathrm{HCl}$ into the outer chamber. After $12 \mathrm{~h}$, the filters were removed, dried at $60^{\circ} \mathrm{C}$ and placed in vials with scintillation fluid containing $100 \mathrm{mg}$ 1,4-di-2(4-methyl-5-phenyloxazolyl)benzene and $2 \mathrm{~g}$ 2,5-diphenyloxazole per litre of toluene. Radioactivity was measured in a scintillation spectrometer. Activity was expressed in units (nmol $\mathrm{CO}_{2}$ evolved $\min ^{-1}$ ). Specific activity was referred to $1 \mathrm{mg}$ protein. All assays were performed on duplicate samples.

Diamine oxidase assay. Diamine oxidase was measured fluorimetrically with homovanillic acid as substrate, essentially as described by Guilbault et al. (1968). In a cuvette, $1 \mathrm{~mm}$-putrescine, 10 units of horseradish peroxidase, $0.47 \mathrm{~mm}$-homovanillic acid and enzyme extract were mixed in a final volume of $3 \mathrm{ml} 0.1 \mathrm{M}$-phosphate buffer $\mathrm{pH} 7.5$ containing $0.1 \mathrm{~mm}-\mathrm{EDTA}$. Fluorescence was measured during 30 min in a Perkin Elmer LS-5B spectrofluorimeter with excitation and emission wavelengths of $315 \mathrm{~nm}$ and $425 \mathrm{~nm}$ respectively. Activity was expressed in units, one unit being the amount of enzyme which oxidizes $1 \mu \mathrm{mol}$ putrescine in $1 \mathrm{~h}$. Specific activity was related to $1 \mathrm{mg}$ protein.

Determination of RNA and protein synthesis. For determination of RNA biosynthesis, spores $\left(5 \times 10^{6} \mathrm{ml}^{-1}\right)$ were inoculated into $2 \mathrm{ml}$ aliquots of liquid YPG medium. At $1 \mathrm{~h}$ intervals, $0.065 \mu \mathrm{Ci}$ of $[5,6-$ ${ }^{3} \mathrm{H}$ ]uracil (sp. act. $40 \mathrm{Ci} \mathrm{mol}^{-1} ; 1.48 \mathrm{TBq} \mathrm{mol}^{-1}$ ) were added, and after $1 \mathrm{~h}$ incubation, the reaction was stopped by the addition of $2 \mathrm{ml}$ icecold $10 \%(\mathrm{w} / \mathrm{v})$ TCA. Samples were incubated on ice for $1 \mathrm{~h}$, filtered through glass-fibre filters (Schleicher and Schüll no. $8,2.5 \mathrm{~mm}$ diameter) and washed with about $60 \mathrm{ml}$ ice-cold $10 \%$ TCA, followed by $60 \mathrm{ml}$ ethanol. Filters were dried at $60^{\circ} \mathrm{C}$ and radioactivity was measured as described above. All assays were performed in duplicate.

To determine protein biosynthesis, spores $\left(5 \times 10^{6} \mathrm{ml}^{-1}\right)$ were inoculated into $2 \mathrm{ml}$ aliquots of liquid synthetic medium plus $0.002 \%$ Casamino acids. At $1 \mathrm{~h}$ intervals, $0 \cdot 140 \mu \mathrm{Ci}$ of a [U-14 C]protein hydrolysate $\left(57 \mathrm{mCi}\right.$ matom $\left.^{-1} ; 2.1 \mathrm{GBq}^{\text {matom }}{ }^{-1}\right)$ were added, and after $1 \mathrm{~h}$ of incubation, the reaction was stopped by addition of $2 \mathrm{ml}$ icecold $10 \%$ TCA and samples were kept on ice for $1 \mathrm{~h}$. Samples were heated in a boiling water bath for $30 \mathrm{~min}$, filtered and processed as described for RNA biosynthesis. All assays were performed on duplicate samples.

Determination of polyamines. Polyamines were measured as described by Calvo-Mendez et al. (1987).
Microscopic observations. Samples of cultures were mixed with an equal volume of $2 \%(\mathrm{v} / \mathrm{v})$ glutaraldehyde in $0.05 \mathrm{M}$-sodium cacodylate buffer and observed under the microscope. Samples for electron microscopy were prepared as described by Ruiz-Herrera et al., (1989).

Miscellaneous. Protein was measured with the Folin reagent. $S$ Adenosylmethionine (SAM), horseradish peroxidase, homovanillic acid, putrescine, hog kidney diamine oxidase and bovine liver catalase were obtained from Sigma. Components for culture media were from Difco. Radioactive compounds were obtained from Amersham. All other reagents were of the highest purity available. Experiments were usually repeated three times, and exceptionally twice. Representative data from reproducible experiments are presented.

\section{Results}

\section{General properties of SAMDC from M. rouxii}

Properties of SAMDC were analysed in the $27000 \mathrm{~g}$ supernatant obtained from cell-free extracts of the fungus. Activity was linearly dependent on time of incubation and protein concentration in the range of $1 \mathrm{~h}$, and up to $0.8 \mathrm{mg}$ protein in the reaction mixture, respectively. Optimum $\mathrm{pH}$ was 7.5 , and optimum temperature, $37^{\circ} \mathrm{C}$. The addition of dithiothreitol to the reaction mixtures did not affect activity, but EDTA addition more than doubled it. Apparently the enzyme is very sensitive to contaminating divalent metals present in the enzyme preparations. The effect of putrescine on SAMDC activity was variable (see below). The inhibitor methylglyoxal bis-(guanylhydrazone) (MGBG) was extremely active against SAMDC: $10 \mu \mathrm{M}-\mathrm{MGBG}$ caused $50 \%$ inhibition of the enzyme activity and $100 \mu \mathrm{M}-$ MGBG about $95 \%$ inhibition. 1,4-Diamino-2-butanone (DAB) and difluoromethylornithine, which are inhibitors of ODC in general (Heby, 1981) including that of $M$. rouxii (Calvo-Mendez et al., 1987) had, as expected, no inhibitory effect on SAMDC activity (but see below).

\section{Effect of putrescine, $D A B$ and $M^{2+}$ on $S A M D C$ activity}

The effect of putrescine on SAMDC activity was variable. Normally, in extracts prepared from 8-9-h-old cultures, addition of putrescine had only a weak stimulatory effect. When younger cultures (less than $6 \mathrm{~h}$ incubation) were used as a source of the enzyme, both putrescine and its analogue DAB stimulated SAMDC activity in cell-free extracts or toluene-permeabilized cells. Higher concentrations of DAB were required to obtain the same degree of stimulation as putrescine, and activation declined at higher DAB concentrations (Fig. 1). DAB also activates SAMDC from Aspergillus nidulans, but to a lesser extent than putrescine (Stevens \& Winther, 1979). The $K_{\mathrm{a}}$ value calculated for putrescine in cell-free extracts was $0.02 \mathrm{~mm}$. These results suggested 


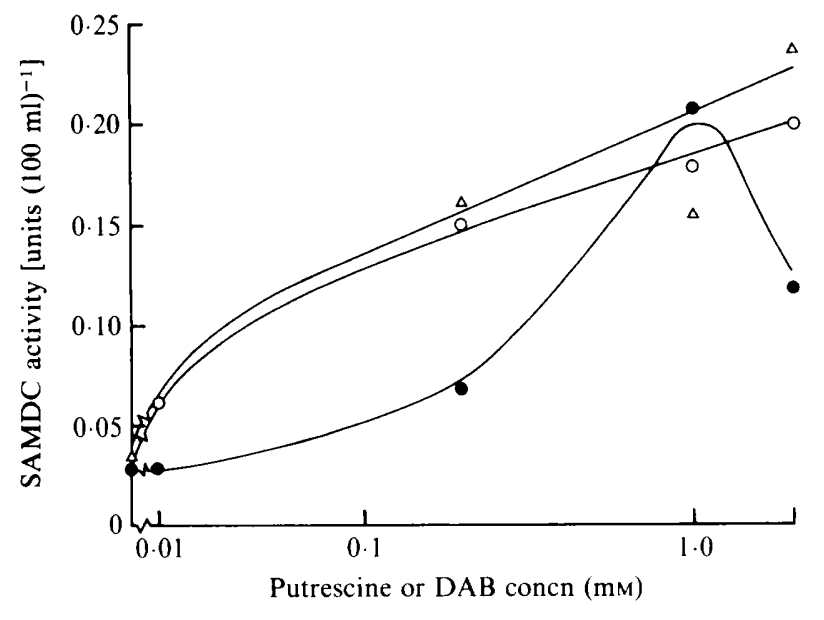

Fig. 1. Effect of putrescine and DAB on SAMDC activity. Cell-free extracts $(O, \boldsymbol{O})$ or toluene-treated cells $(\triangle)$ were incubated in the presence of variable concentrations of putrescine $(O, \triangle)$ or DAB $(\boldsymbol{O})$, and SAMDC activity was measured as described in Methods.

the presence of two forms of the enzyme, one stimulated, and another one unaffected by putrescine. $\mathrm{Mg}^{2+}$ did not stimulate SAMDC activity of toluene-permeabilized cells which had been grown for 3 or $6 \mathrm{~h}$ (not shown).

Suresh \& Adiga (1977) have shown that in Lathyrus sativus seedlings activation of SAM-decarboxylase by putrescine was artifactually due to chemical decarboxylation of SAM by $\mathrm{H}_{2} \mathrm{O}_{2}$ generated through the action of diamine oxidase. Accordingly, we analysed whether putrescine activation of SAM-decarboxylase was due to a similar phenomenon in $M$. rouxii. Firstly we measured the levels of diamine oxidase in 3 and $7 \mathrm{~h}$-old germlings of the fungus. It was observed that in agreement with previous data SAMDC from $3 \mathrm{~h}$-old cells was activated to a higher degree (about fourfold more) than the enzyme from $7 \mathrm{~h}$-old cells. On the other hand diamine oxidase levels were higher in older cells (data not shown). As a second approach we determined whether a large excess of exogenous diamine oxidase or hydrogen peroxide increased the levels of SAM decarboxylation by cell-free extracts of $M$. rouxii. We also tested whether catalase decreased the putrescine-activatable liberation of $\mathrm{CO}_{2}$ from SAM. Addition of diamine oxidase or $\mathrm{H}_{2} \mathrm{O}_{2}$ increased SAM decarboxylation, but only by about $40 \%$, whereas catalase decreased it by $13 \%$ (Table 1). Finally we compared SAM decarboxylase activity of toluenepermeabilized cells under an atmosphere of nitrogen, with that under normal aerobic assay conditions. SAMDC activity was about the same under either condition (data not shown).

\section{Development of SAMDC activity during germination of sporangiospores of $M$. rouxii}

Activity of SAMDC was measured at different times in germinating cultures of $M$. rouxii. Ungerminated spores had no detectable levels of the enzyme. Total SAMDC activity increased exponentially upon incubation of the spores in minimal medium. After $1 \mathrm{~h}$ incubation, specific activity increased to more than one-third of the maximal specific activity which was attained after $4 \mathrm{~h}$ incubation, when about $40 \%$ of the spores had germinated (Fig. 2). After this time specific but not total enzyme activity started to decline.

When SAMDC activity was measured in the presence or absence of putrescine during germination in minimal, medium it was observed that at early periods of incubation the enzyme was strongly activated by the

Table 1. Effect of different additions on SAM decarboxylation by cellfree extracts of $M$. rouxii

Cell-free extracts from 7-h-old mycelium were incubated in standard assay mixtures for determination of SAMDC. Where indicated, 0.15 units of hog kidney diamine oxidase, $0 \cdot 1 \mu \mathrm{mol}$ of $\mathrm{H}_{2} \mathrm{O}_{2}, 100$ units of bovine liver catalase per assay, or $1 \mathrm{~mm}$-putrescine were added to the incubation mixtures. After incubation for $60 \mathrm{~min}$ at $37^{\circ} \mathrm{C}$, radioactive ${ }^{14} \mathrm{CO}_{2}$ evolved was measured as described in Methods.

\begin{tabular}{lccc}
\hline \multicolumn{1}{c}{$\begin{array}{c}\text { Additions to } \\
\text { extract }\end{array}$} & $\begin{array}{c}\text { Protein per } \\
\text { assay } \\
(\mathrm{mg})\end{array}$ & $\begin{array}{c}{ }^{1+} \mathrm{CO}_{2} \text { liberated } \\
\text { (c.p.m.) }\end{array}$ & $\begin{array}{c}\text { Activation } \\
\text { or inhibition } \\
(\%)\end{array}$ \\
\hline None & 1.29 & 1759 & - \\
Diamine oxidase & 1.29 & 2429 & +38 \\
$\mathrm{H}_{2} \mathrm{O}_{2}$ & 1.29 & 2501 & +42 \\
Putrescine & 0.5 & 1189 & - \\
Putrescine + catalase & 0.5 & 1044 & -13 \\
\hline \hline
\end{tabular}



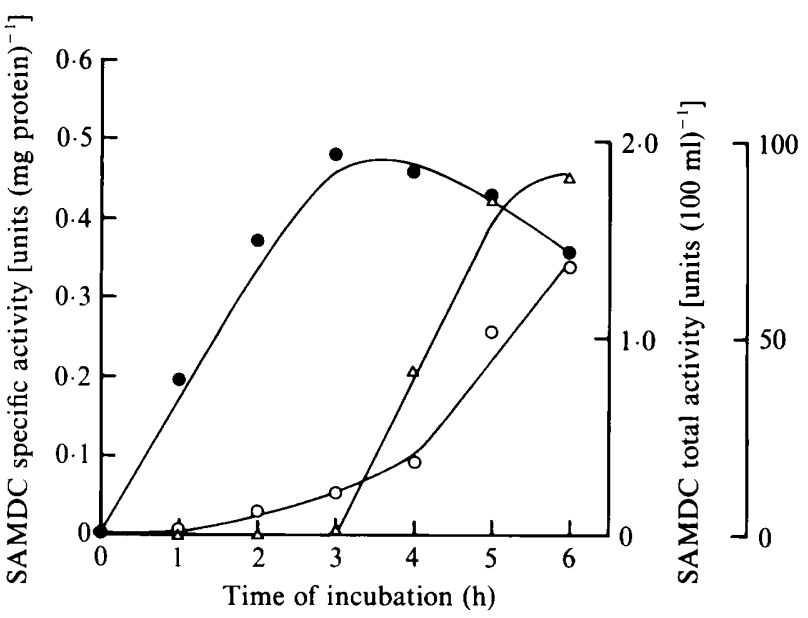

Fig. 2. Synthesis of SAMDC during sporangiospore germination. Spores were inoculated into minimal medium. At timed intervals, samples were recovered for determination of spore germination, cell protein and SAMDC activity in toluene-treated samples in the presence of $1 \mathrm{~mm}$-putrescine. - SAMDC specific activity; $O$, SAMDC total activity (per $100 \mathrm{ml}$ medium); $\triangle$, spore germination.

polyamine, about 12-fold in 2-or 3-h-old cells, whereas in 6-7-h-old cells, putrescine produced less than twofold activation of the enzyme (Fig. $3 a$ ). Results expressed as differential rate of synthesis of the enzyme show that after a short delay, putrescine-activatable SAMDC is synthesized as an exponentially increasing fraction of total cell protein. At later times a decline in the rate of synthesis is observed, whereas an increase in the putrescine-insensitive enzyme was noticed (Fig. $3 b$ ).

To determine whether the putrescine-insensitive activity came from a permanent activation of the enzyme brought about by the putrescine accumulated at late periods of incubation (Ruiz-Herrera \& Calvo-Mendez, 1987), we permeabilized 3-h-old cells with toluene and incubated them with or without putrescine. After $30 \mathrm{~min}$ at $25^{\circ} \mathrm{C}$, cells were washed, and SAMDC activity was measured in the presence or in the absence of putrescine. SAMDC was equally activated by putrescine, independently of whether or not the permeabilized cells had been incubated with the polyamine. We also explored the possibility that the putrescine-insensitive enzyme was the result of a post-translational modification of SAMDC. To test this hypothesis, spores were incubated in liquid YPG medium for $3 \mathrm{~h}$, and then the culture was divided into two batches. One was treated with $100 \mu \mathrm{g}$ cycloheximide $\mathrm{ml}^{-1}$, the other remained as a control. At this time and after a further 2 and $4 \mathrm{~h}$ incubation, samples were removed to measure cell protein and SAMDC activity. SAMDC activity in cycloheximide-treated cells remained activatable by
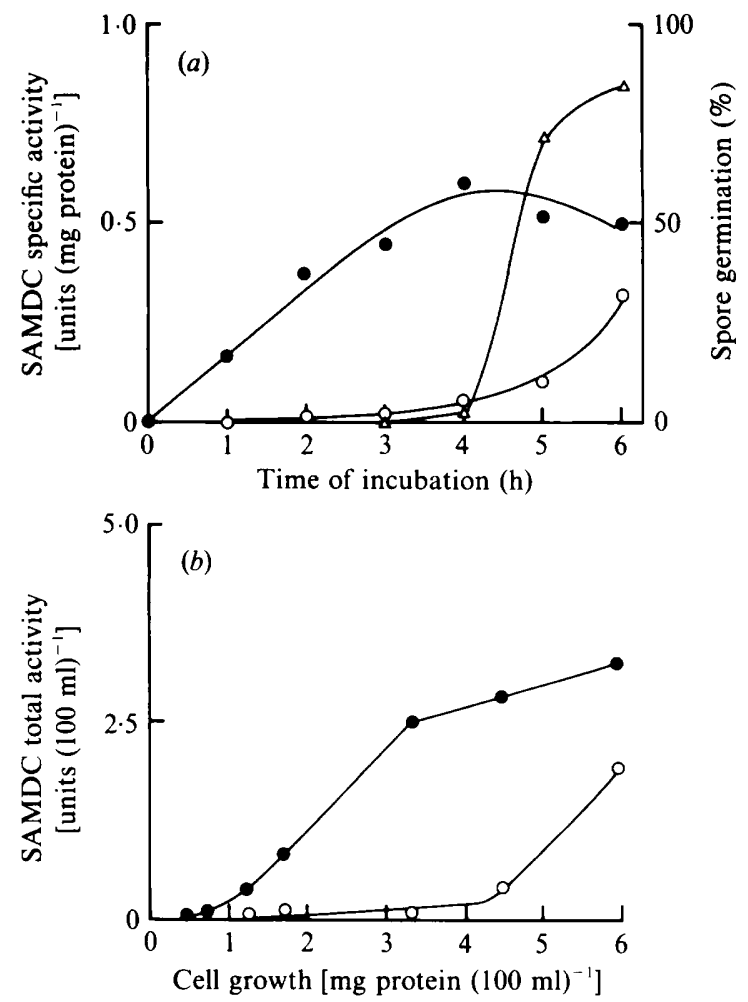

Fig. 3. Development of putrescine-stimulated and putrescine-insensitive SAMDC activities during sporangiospore germination. Spores were inoculated into minimal medium. At timed intervals, samples were recovered for determination of spore germination $(\triangle)$, cell protein and SAMDC activity in toluene-treated samples both in the absence $(O)$ or in the presence (O) of $1 \mathrm{~mm}$-putrescine. (a) Development of SAMDC as a function of time of incubation. (b) Differential rate of synthesis of SAMDC.

putrescine in the same order of magnitude after 2 and $4 \mathrm{~h}$ incubation with the drug, although total activity declined somewhat. Cells growing in the absence of cycloheximide synthesized the putrescine-insensitive SAMDC as suggested by the fact that after $4 \mathrm{~h}$ incubation, activity of the enzyme measured in the absence of putrescine increased 20-fold, against a threefold increase in the activity measured in the presence of putrescine (Table 2 ).

\section{Effect of MGBG on cell growth and synthesis of macromolecules}

Addition of MGBG to synthetic medium at concentrations in the range which inhibited SAMDC activity by more than $90 \%$ (see above) did not affect growth of the fungus, probably because MGBG has a low permeability. On the other hand, addition of 5 mM-MGBG inhibited growth almost completely. For SAMDC from Acanthamoeba culbertsoni MGBG had a $K_{\mathrm{i}}$ of $123 \mu \mathrm{M}$ 
Table 2. Effect of cycloheximide on the formation of putrescine-insensitive SAMDC

Spores were incubated for $3 \mathrm{~h}$ in YPG medium and then divided into two samples. One received $100 \mu \mathrm{g}$ cycloheximide $\mathrm{ml}^{-1}$ and the other remained as a control. Samples were removed to determine germination, cell protein and SAMDC activity, and the rest of the cultures were incubated further. After 2 and $4 \mathrm{~h}$, samples were recovered to measure the same parameters. SAMDC activity is expressed as described in Methods.

\begin{tabular}{cccccc}
\hline \hline $\begin{array}{c}\text { Time of } \\
\begin{array}{c}\text { incubation } \\
(\mathrm{h})\end{array}\end{array}$ & $\begin{array}{c}\text { Cycloheximide } \\
\text { added }\end{array}$ & $\begin{array}{c}\text { Spore } \\
\text { germination } \\
(\%)\end{array}$ & $\begin{array}{c}\text { Cell protein } \\
{\left[\mathrm{mg}(100 \mathrm{ml})^{-1}\right]}\end{array}$ & \multicolumn{2}{c}{$\begin{array}{c}\text { Total SAMDC activity } \\
\text { [units }\left(100 \mathrm{ml}^{-1}\right]\end{array}$} \\
\hline 3 & No & 0 & 1.37 & 0.049 \\
putrescine & $\begin{array}{c}\text { Plus } \\
\text { putrescine }\end{array}$ \\
5 & No & 78 & 5.50 & 0.313 & 0.752 \\
7 & Yes & 0 & 1.29 & 0.032 & 0.309 \\
& No & 95 & 15.62 & 0.921 & 2.59 \\
& Yes & 0 & 1.50 & 0.031 & 0.460 \\
\hline \hline
\end{tabular}

(Gupta et al., 1987), but a concentration of $2.5 \mathrm{~mm}$ was necessary to inhibit growth of the amoeba (Gupta et al., 1986).

Microscopic observations of inhibited cultures showed that spores became spherical with a mean diameter close to that of the large axis of the normal ellipsoidal sporangiospores (Fig. 4c), and did not proceed beyond this point in the germination process, in contrast to normal cells which after $3 \mathrm{~h}$ had enlarged significantly (Fig. $4 a$ ) and germinated after 4-5 h (Fig. $4 b$ ). Fig. $4(d)$ shows the structure of a spore incubated for $12 \mathrm{~h}$ in the presence of MGBG. Inhibited cells did not increase in size, and appeared nearly spherical. The cell wall was relatively thick and with alternating electron-transparent and electron-opaque zones. The internal structure was relatively unaffected by the drug, except for the vacuole. Prolonged periods of incubation (more than $12 \mathrm{~h}$ ) gave rise to severe alterations in the cell structure and eventually to cell lysis. Removal of MGBG at shorter periods of incubation (about 6-8 h) reversed the inhibition phenomenon, and spores germinated almost normally. Addition of polyamines to cultures grown in synthetic medium in the presence of MGBG partially reversed the inhibitory effect of the drug. Accordingly, $5 \mathrm{~mm}$-putrescine or $5 \mathrm{~mm}$-spermidine allowed 10 or $25 \%$ spore germination respectively. A mixture of spermidine plus putrescine was most effective, permitting about $60 \%$ germination. However, germination in all these cases was atypical, with production of distorted cells.

Interestingly, the period of sensitivity of $M$. rouxii cells to MGBG was limited to the first $2 \mathrm{~h}$ of the germination process in synthetic medium. When the drug was added after this time to germinating spores, they were completely unaffected and grew normally (Table 3 ).
Table 3. Period of sensitivity of spore germination to $M G B G$

Spores were inoculated into flasks containing liquid synthetic medium. At the indicated times, $5 \mathrm{~mm}-\mathrm{MGBG}$ was added to five duplicate cultures; one duplicate remained as a control without MGBG. After $24 \mathrm{~h}$ incubation, germination and cell dry weight were measured. Data are mean values.

\begin{tabular}{ccc}
\hline \hline $\begin{array}{c}\text { Time of MGBG } \\
\text { addition } \\
\text { (h) }\end{array}$ & $\begin{array}{c}\text { Spore } \\
\text { germination } \\
(\%)\end{array}$ & $\begin{array}{c}\text { Cell growth } \\
\left.\text { [mg dry wt }(100 \mathrm{ml})^{-1}\right]\end{array}$ \\
\hline 0 & 0 & $1 \cdot 14$ \\
1 & 0 & $0 \cdot 28$ \\
2 & 20 & $2 \cdot 76$ \\
3 & 100 & $22 \cdot 0$ \\
5 & 100 & $23 \cdot 0$ \\
- & 100 & $21 \cdot 60$ \\
\hline \hline
\end{tabular}

Determination of the effect of MGBG on the synthesis of RNA and protein demonstrated that the rate of RNA biosynthesis was only slightly affected by the drug during the first hour of incubation, it was reduced by more than $50 \%$ during the second hour and was almost completely abolished after this time (not shown). Similarly, the rate of protein biosynthesis was almost unaffected during the first hour of the germination process, decreased to about $50 \%$ during the second hour, and inhibition was almost complete after this time (not shown).

\section{Effect of $M G B G$ on polyamine biosynthesis}

In normal cells, a rapid increase in the levels of spermidine occurs during the first hours of germination. 

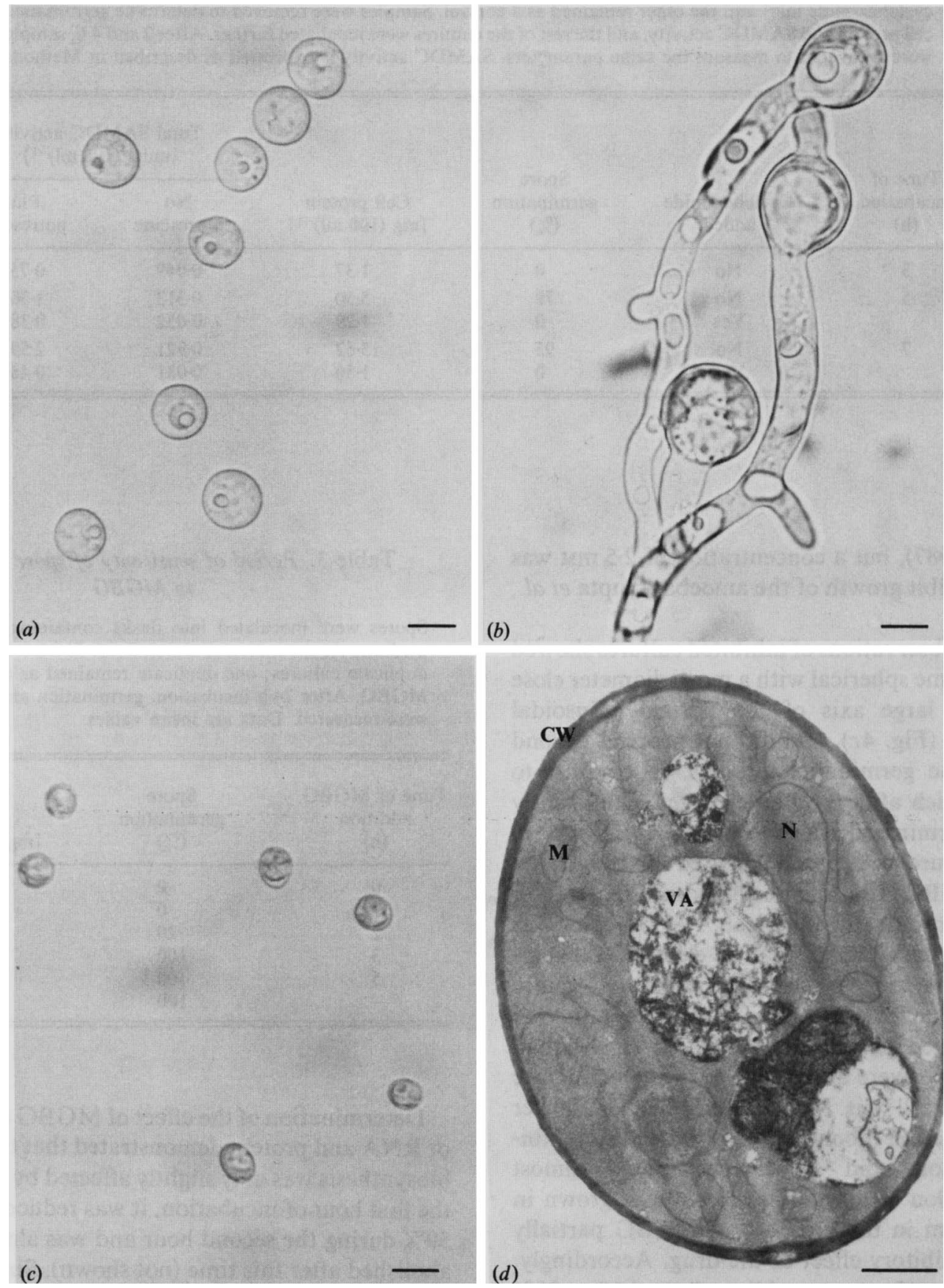

Fig. 4. Effect of MGBG on spore morphology. (a) Enlarged normal spores after $3 \mathrm{~h}$ of incubation. Bar, $10 \mu \mathrm{m}$. (b) Normal germlings grown for $6 \mathrm{~h}$. Bar, $10 \mu \mathrm{m}$. (c) MGBG-treated cells incubated for $6 \mathrm{~h}$. Notice their small size and their almost spherical shape. Bar, $10 \mu \mathrm{m}$. (d) Electron micrograph of a thin section of a MGBG-treated cell incubated for $12 \mathrm{~h}$ in the presence of the drug. Notice the relatively thick cell wall with alternating electron-transparent and electron-dense zones. $\mathrm{N}$, nucleus, $\mathrm{M}$, mitochondrion; VA, vacuole; $\mathrm{CW}$, cell wall. Bar, $1 \mu \mathrm{m}$. 


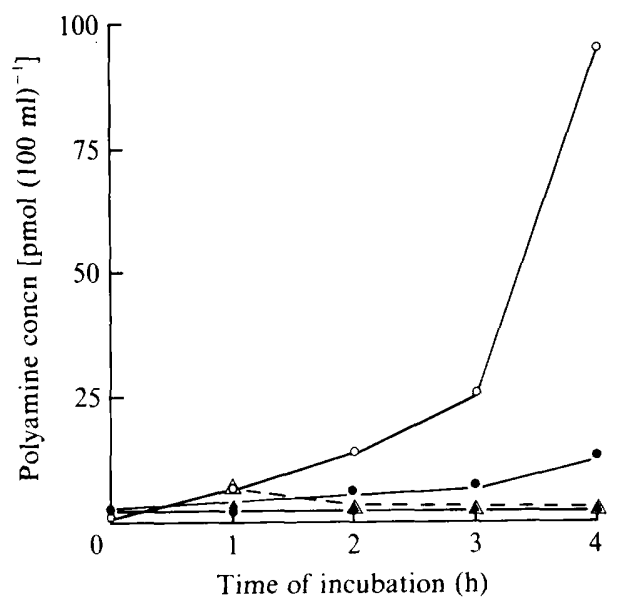

Fig. 5. Effect of MGBG on polyamine biosynthesis by germinating spores. Spores were incubated in YPG medium with $(\triangle, \boldsymbol{\Delta})$ or without $(O$, ) $5 \mathrm{~mm}-\mathrm{MGBG}$. At intervals, samples were recovered for determination of cell protein and polyamines.,$\Delta$, Putrescine; $O$, $\triangle$, spermidine. Concentrations are expressed as pmol per $100 \mathrm{ml}$ aliquots.

The level then decreases. In contrast, accumulation of putrescine is delayed (Fig. 5). Apparently all putrescine synthesized during the initial periods of germination is rapidly utilized for spermidine biosynthesis. Addition of MGBG to spores inhibited the biosynthesis of spermidine and, indirectly, that of putrescine (Fig. 5). Since it inhibits protein biosynthesis it must block the increase in ODC formation which occurs at a late period of spore growth (Calvo-Mendez et al., 1987).

\section{Discussion}

The results presented in this communication show that SAMDC is finely regulated during the germination of $M$. rouxii sporangiospores. In the initial periods of germination SAMDC activity increases. SAMDC is stimulated by putrescine, but not by $\mathrm{Mg}^{2+}$. The possibility that activation of SAM decarboxylation by putrescine was artefactually due to $\mathrm{H}_{2} \mathrm{O}_{2}$ produced by oxidation of the diamine, as found in Lathyrus sativus (Suresh \& Adiga, 1977) was ruled out. In fact Suresh \& Adiga (1977) described putrescine-dependent SAMDCs from other sources which were not artefactual and concluded that the observation in L. sativus was not a general phenomenon.

The differential rate of synthesis of the putrescinedependent enzyme changes before initiation of growth phase II. At the same time a second SAMDC activity which is insensitive to both $\mathrm{Mg}^{2+}$ and putrescine starts to increase. All organisms studied thus far contain a single SAMDC activity stimulated by either putrescine or
$\mathrm{Mg}^{2+}$, or non-stimulatable by either effector (Pegg, 1984). Thus in this sense $M$. rouxii departs from the rule. The appearance of the second (putrescine insensitive) SAMDC activity is not the result of a permanent activation of the enzyme by the polyamine, but requires protein biosynthesis de novo, suggesting that it represents a different enzyme from the one which does respond to putrescine.

Causing polyamine shortage by the addition of the SAMDC inhibitor MGBG revealed the following. Firstly, the drug stopped the germination process at stage Ia, confirming our previous data that growth phases Ia and Ib represent different developmental stages during sporangiospore germination (Cano \& Ruiz-Herrera, 1988). This effect was reversed by elimination of the drug or by polyamine addition. The drug did not significantly affect protein biosynthesis, and only slightly inhibited RNA biosynthesis during the time required to complete growth phase Ia, but it severely blocked the biosynthesis of both macromolecules after this time. MGBG inhibited polyamine biosynthesis in the fungus, and this is probably the basis for its inhibitory action in Mucor development. MGBG inhibits spermidine formation in mammary explants from mid-pregnant mice, and as a consequence blocks the stimulation of milk protein biosynthesis exerted by the combined action of insulin, hydrocortisone and prolactin (Oka \& Perry, 1974). MGBG has also been shown to inhibit cell growth of Entamoeba histolytica (Kaul et al., 1985) and Acanthamoeba culbertsoni (Gupta et al., 1986), to block DNA biosynthesis in several animal systems, and to interfere in the cell cycle in different cell cultures (Pegg \& McCann, 1982).

One important observation was that the effect of MGBG on spore germination was time-dependent. There was a 'window' of sensitivity to the drug restricted to the first $2 \mathrm{~h}$ of incubation. Addition of the drug after this time only delayed cell growth, so that after $24 \mathrm{~h}$ drugtreated cells were indistinguishable from untreated cells. We have reported similar results for the effect of DAB (an inhibitor of ODC) on the germination of Mucor spores (Ruiz-Herrera et al., 1987). DAB addition decreases the levels of polyamines and stops development in growth phase $\mathrm{Ib}$, preventing germ tube emergence, but addition of the drug after a critical time period has no further effect on cell growth. Based on these results it seems attractive to hypothesize that spermidine, but not putrescine, is required at an early stage of development to permit the expression of genes necessary for the establishment of growth phase Ib. In contrast, putrescine, but not spermidine, is required at a later step in development to inhibit DNA methylation and permit gene expression required for the establishment of the phase of polarized growth (Cano et al., 1988). 
Part of this work was supported by financial help from DIGICySA of the Subsecretaria de Educacion Superior e Investigacion Cientifica, SEP, and the Consejo Nacional de Ciencia y Tecnologia, Mexico. Thanks are given to Dr Marisela Morales-Chirino and Mr Armando Obregon-Herrera for electron microscopic studies. Jose Ruiz-Herrera is National Investigator, Mexico.

\section{References}

Bartnicki-Garcia, S. \& Lippman, E. (1977). Polarization of cell wall synthesis during spore germination. Experimental Mycology 1, 230240.

Bartnicki-Garcia, S. \& Nickerson, W. J. (1962). Nutrition, growth and morphogenesis of Mucor rouxii. Journal of Bacteriology 84, 841858.

Calvo-Mendez, C., Martinez-Pacheco, M. \& Ruiz-Herrera, J. (1987). Regulation of ornithine decarboxylase activity in Mucor bacilliformis and Mucor rouxii. Experimental Mycology 11, 270-277.

Cano, C. \& Ruiz-Herrera, J. (1988). Developmental stages during the germination of Mucor sporangiospores. Experimental Mycology 12, 47-59.

Cano, C., Herrera-Estrella, L. \& Ruiz-Herrera, J. (1988). DNA methylation and polyamines in regulation of development of the fungus Mucor rouxii. Journal of Bacteriology 170, 5946-5948.

Guilbault, G. G., Brignac, P. \& Zimmer, M. (1968). Homovanillic acid as a fluorometric substrate for oxidative enzymes. Analytical applications of the peroxidase, glucose oxidase, and xanthine oxidase systems. Analytical Chemistry 40, 190-196.

Gupta, S., SRIvastava, D. K. \& Shukla, O. P. (1986). Inhibition of polyamine metabolism induces encystation in Acanthamoeba culbertsoni. Current Science 55, 732-734.
Gupta, S., Shukla, O. P. \& Walter, R. D. (1987). Putrescineactivated $S$-adenosylmethionine decarboxylase from Acanthamoeba culbertsoni. Molecular and Biochemical Parasitology 23, 247-252.

HEBY, O. (1981). Role of polyamines in the control of cell proliferation and differentiation. Differentiation 19, 1-20.

Kaul, S. M., Imam, S. A. \& Shukla, O. P. (1985). Growth inhibition of E. histolytica by methylglyoxal bis-(guanylhydrazone). Current Science 54, 800-807.

Nickerson, K. W., Dunkie, L. D. \& van Etten, J. L. (1977). Absence of spermine in filamentous fungi. Journal of Bacteriology 129, 173176.

OKa, T. \& Perry, J. W. (1974). Spermidine as possible mediator of glucocorticoid effect on milk protein synthesis in mouse mammary epithelium in vitro. Journal of Biological Chemistry 249, 7647-7652.

PegG, A. E. (1984). S-Adenosylmethionine decarboxylase: a brief review. Cell Biochemical Function 2, 11-15.

PEGG, A. E. (1986). Recent advances in the biochemistry of polyamines in eukaryotes. Biochemical Journal 234, 249-262.

Pegg, A. E. \& MCCANN, P. P. (1982). Polyamine metabolism and function. American Journal of Physiology 243 (Cell Physiology 12), $\mathrm{C} 212-\mathrm{C} 221$.

Ruiz-Herrera, J. \& Calvo-Mendez, C. (1987). Effect of ornithine decarboxylase inhibitors on the germination of sporangiospores of Mucorales. Experimental Mycology 11, 287-296.

Ruiz-Herrera, J., Valenzuela, C., Martinez-Cadena, G. \& OBREGON, A. (1989). Alterations in the vesicular pattern and wall growth of Phycomyces induced by the calcium ionophore A23187. Protoplasma 148, 15-25.

Stevens, L. \& WinTHER, M. D. (1979). Spermine, spermidine and putrescine in fungal development. Advances in Microbial Physiology 19, 63-148.

SURESH, M. R. \& AdigA, P. R. (1977). Putrescine-sensitive (artifactual) and insensitive (biosynthetic) $S$-adenosyl-L-methionine decarboxylase activities of Lathyrus sativus seedling. European Journal of Biochemistry 79, 511-518.

TABOR, C. W. \& TABOR, H. (1984). Polyamines. Annual Review of Biochemistry 55, 749-790. 